\title{
OPEN Volatile organic compounds as a potential screening tool for neoplasm of the digestive system: a meta-analysis
}

\author{
Lixing Wang ${ }^{1}$, Junan $\mathrm{Li}^{2}$, Xiaoliang Xiong ${ }^{1}$, Tingting Hao ${ }^{1}$, Chao Zhang ${ }^{1}$, Zhao Gao ${ }^{1}$, \\ Lili Zhong ${ }^{3,4 \bowtie}$ \&Yinlong Zhao ${ }^{1,4} \llbracket$
}

This meta-analysis was aimed to estimate the diagnostic performance of volatile organic compounds (VOCs) as a potential novel tool to screen for the neoplasm of the digestive system. An integrated literature search was performed by two independent investigators to identify all relevant studies investigating VOCs in diagnosing neoplasm of the digestive system from inception to 7th December 2020. STATA and Revman software were used for data analysis. The methodological quality of each study was assessed using the Quality Assessment of Diagnostic Accuracy Studies tool. A bivariate mixed model was used and meta-regression and subgroup analysis were performed to identify possible sources of heterogeneity. A total of 36 studies comprised of 1712 cases of neoplasm and 3215 controls were included in our meta-analysis. Bivariate analysis showed a pooled sensitivity of 0.87 ( $95 \%$ confidence interval $(\mathrm{Cl}) 0.83-0.90)$, specificity of $0.86(95 \% \mathrm{Cl} 0.82-0.89)$, a positive likelihood ratio of $6.18(95 \% \mathrm{Cl} 4.68-8.17)$, and a negative likelihood ratio of $0.15(95 \% \mathrm{Cl} 0.12-0.20)$. The diagnostic odds ratio and the area under the summary ROC curve for diagnosing neoplasm of the digestive system were $40.61(95 \% \mathrm{Cl} 24.77-66.57)$ and $0.93(95 \% \mathrm{Cl} 0.90-0.95)$, respectively. Our analyses revealed that VOCs analysis could be considered as a potential novel tool to screen for malignant diseases of the digestive system.

The incidence of the digestive system neoplasm is rising yearly worldwide. These tumors including colorectal cancer, stomach cancer, liver cancer, etc. have been associated high risk of morbidity and mortality based on the Global Cancer Statistics $2018^{1}$. Thus, early detection and timely treatment are integral for a favorable prognosis and long-term survival. At present, tumor markers have been widely used for tumor screening and diagnosis, monitoring treatment response, and surveillance of tumor recurrence after treatment. In clinical practice, markers commonly used to screen and diagnose tumors of the digestive system are mostly derived from blood, including carbohydrate antigen (CA50, 199, 242, 724), alpha-fetoprotein (AFP), carcinoembryonic antigen (CEA), pepsinogen, etc. However, the sensitivity and specificity of a single tumor marker are suboptimal, and it is often necessary to combine several tumor markers for the screening and early diagnosis of tumors ${ }^{2-5}$. Of course, there are also circulating tumor DNA and methylated genes from blood, urine or feces that are still being evaluated. Although these have shown good performance in the diagnosis of tumors of the digestive system, they have not been widely used in clinical practice due to immaturity in technology and high cost. Nevertheless, endoscopic examination with biopsy remains the gold standard for the diagnosis of gastric, esophageal, and colorectal cancers, while endoscopic ultrasonography and other imaging examinations can be used for the diagnosis of liver and pancreatic cancer. However, endoscopic screening and diagnostic approaches have limitations, including patient discomfort and potential major complications and harms. Therefore, an effective noninvasive screening tool for malignancies of the digestive system malignancies is desired.

Breath analysis is recognized as a simple and non-invasive method for screening and monitoring pathology or disease. Nevertheless, studies have shown that volatile organic compounds (VOCs) from urine also demonstrated good performance in the screening of cancer, in particular, special phenotypes of VOCs in urine could be

\footnotetext{
${ }^{1}$ Department of Nuclear Medicine, The Second Hospital of Jilin University, Changchun 130041, China. ${ }^{2}$ Gastroenterology and Center of Digestive Endoscopy, The Second Hospital of Jilin University, Changchun 130041, China. ${ }^{3}$ Jilin Provincial Key Laboratory on Molecular and Chemical Genetic, The Second Hospital of Jilin University, Changchun 130041, China. ${ }^{4}$ These authors contributed equally: Lili Zhong and Yinlong Zhao. ${ }^{\varpi}$ email: zhongll@jlu.edu.cn; yinlong@jlu.edu.cn
} 
used for the screening of prostate and gastrointestinal cancers ${ }^{6}$. Contrary to the conventional biomarker studies subjected to the health status of the individuals, the analysis of VOCs reflects the fingerprint characteristics of individuals that represent an instance of individualized medicine ${ }^{7}$. Moreover, a variety of sensor technologies are now being applied in analyzing the patterns of VOCs, such as eNoses and nanomaterials. As technology advances and clinical research progresses, VOCs analysis does not only enable early detection of cancer, but also the monitoring of the response to cancer therapy and detection of disease recurrence early when secondary treatments are most effective ${ }^{8}$.

VOCs are organic compounds with relatively low molecular weight and high vapor pressure. Cancer-originated VOCs have been frequently detected in feces, urine, blood, skin, sweat, and gases exhaled from cancer patients. These have been produced by tumor cells, which can reflect the disease ${ }^{9-11}$. Therefore, it is vital to explore the differences in VOCs released by varying cancer types to identify specific representative VOCs to each tumor that can be used as a diagnostic tool. For instance, the study by Kumar et al. ${ }^{12}$ has shown significantly lower concentrations of several specific volatile compounds in non-tumor individuals than those with tumors.

VOCs reflect changes in pathology and metabolic processes ${ }^{13,14}$. These specific VOCs have been considered to be the results of an imbalance between the systemic manifestations of oxidative stress, metabolic abnormalities, or reactive oxygen and the ability of the biological system to detoxify or repair damages ${ }^{15-17}$. In particular, the gut microbiome plays a key role in diseases of the digestive system, including colorectal cancer and inflammatory bowel disease. Changes in the composition of gut bacterial flora affect the fermentation products and the forms of volatile organic compounds (VOCs). Given that different diseases are associated with specific metabolomics that reflects cell metabolism, providing a new way of thinking for the diagnosis of diseases. In fact, in inflammatory bowel disease, changes in the gut microbiome are associated with colonic inflammation and can influence VOCs production. Also, some bacterial communities have been implicated in the development of colorectal cancer ${ }^{18-21}$. At the cellular level, changes in the production of VOCs have been associated with oxidation of polyunsaturated acids in the cell membrane as a result of genetic and/or protein mutations within tumor cells and the increased relative incidence of reactive oxygen species within cancer cells ${ }^{22,23}$. These cancer-related volatile organic compounds are released from the affected tissues into the feces or bloodstream and eventually excreted either through breath or through urine or feces ${ }^{14}$. Therefore, VOCs, as a comparatively new and non-invasive biomarker, provides a promising and attractive option for the screening of tumors in the digestive system.

Several studies have shown that VOCs analysis is valuable in the diagnosis of tumors of the digestive system $^{24-26}$. However, these studies have some shortcomings, with some only analyzing VOCs in exhaled gas, while others had too a small sample size. In our meta-analysis, VOCs from all sources and tumors of the digestive tract were summarized and analyzed. This would ascertain the diagnostic efficacy of VOCs for tumors of the digestive system.

\section{Materials and methods}

Search strategy. A comprehensive, systematic electronic literature search of PubMed and Web of Science was conducted to identify all relevant papers from inception to $7^{\text {th }}$ December 2020. Search terms were as follows: volatile organic compounds or VOCs and esophageal neoplasm or esophageal cancer or gastric cancer or gastric neoplasm or liver cancer or liver neoplasm or hepatic neoplasm or pancreas cancer or pancreas neoplasm or colorectal cancer or colorectal neoplasm. All relevant literature was also screened for other possible studies.

Study selections. All articles were reviewed by two independent investigators according to the inclusion and exclusion criteria. The inclusion criteria were: (1) VOCs were used to detect patients with neoplasm of the digestive system; (2) the control group consisted of patients with benign diseases of the digestive system and/or healthy individuals; (3) patients did not undergo any therapy; (4) extracted data could be used to measure truepositive (tp), false-positive (fp), false-negative (fn), and true-negative (tn) values. Studies/articles were excluded for the following criteria: (1) studies not within the field of our research; (2) non-human or animal study; (3) non-English literature; (4) non-diagnostic study; (5) studies on the neoplasm of not the digestive system; (6) data from the study were insufficient to constitute $2 \times 2$ tables; (7) review articles, editorials, case reports, conference proceedings, or letters.

Data extraction. For each study included in our meta-analysis, the following data were extracted: first author, country, year of publication, number of participants, mean age of participants, percentage of males, cancer type, the source of VOCs, analytical platforms, and the control group. Also, each investigator registered and counted the numbers of $\mathrm{tp}, \mathrm{fp}, \mathrm{tn}$, and $\mathrm{fn}$. (Based on the criteria of diagnostic tests, we used the pathological results as the gold standard and then classified the results as true positive (tp), false positive (fp), true negative $(\mathrm{tn})$ and false negative $(\mathrm{fn})$ according to the degree of matching between the results obtained by pathology and VOCs analysis. Sensitivity was calculated as $\mathrm{tp} /(\mathrm{tp}+\mathrm{fn})$, while specificity was calculated as $\mathrm{tn} /(\mathrm{tn}+\mathrm{fp})$. Correspondingly, four basic data could be extracted from the known sensitivity and specificity. Any disagreements between the investigators were assessed by a third reviewer and resolved by mutual agreement.

Quality assessment. To assess the quality of the included studies, the Quality Assessment of Diagnostic Accuracy Studies 2 (QUADAS-2) tool ${ }^{27}$ was used, which was an evidence-based quality assessment tool for systematic reviews of diagnostic accuracy studies that included four domains: patient selection, index test, reference standard, and flow and timing.

Statistical analysis. Heterogeneities between the studies were evaluated by measuring the $P$-value of the Cochran-Q test and I-square statistic ${ }^{28}$. Studies were considered homogenous if $P>0.05$ and $\mathrm{I}^{2} \leq 50 \%$, and we 
589 records were identified through online databases including

86 from PubMed, 503 from web of science

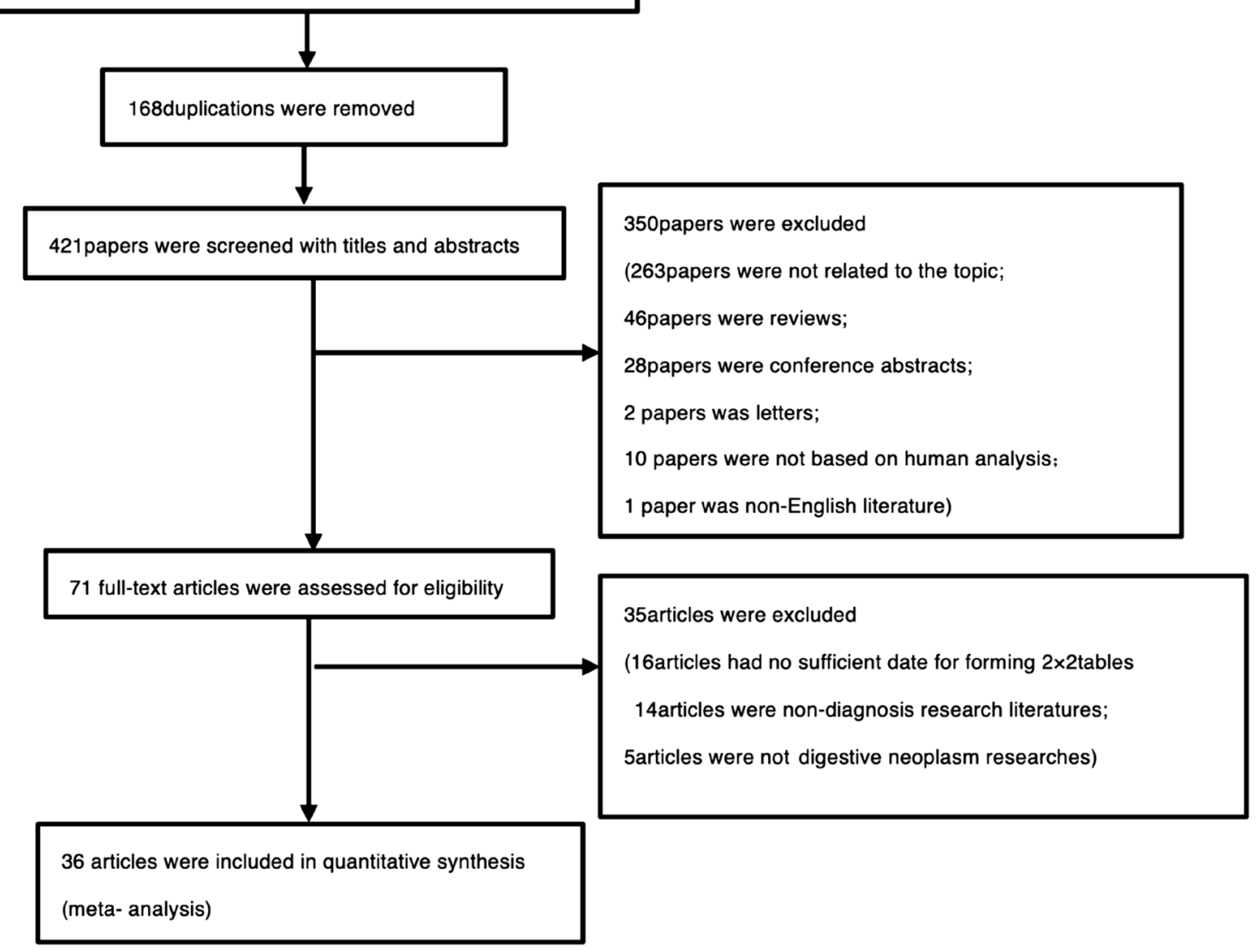

Figure 1. Flow diagram of the study selection process.

performed only pooled sensitivity, specificity, positive likelihood ratio (PLR), negative likelihood ratio (NLR), and diagnostic odds ratio (DOR). If $P<0.05$ or $\mathrm{I}^{2} \geq 50 \%$, indicating statistically significant heterogeneity between the studies, further meta-regression and subgroup analysis were carried out to determine the possible sources of heterogeneity.

Sensitivity, specificity, accuracy, positive and negative predictive values, PLR, NLR, and DOR of VOCs in the diagnosis of digestive system neoplasm were obtained from the individual study, and forest plots were used to calculate and graphically display pooling of the data. The SROC curve was displayed to obtain the optimal diagnostic efficiency for VOCs, and the area under the summary ROC curve (AUC) was calculated. The publication bias was presented by using the Deeks' funnel plot asymmetry test. Meta-analysis was performed using STATA15.0 (StataCorp, College Station, TX, USA) with the MIDAS module, while RevMan 5.4 (Revman, the Cochrane Collaboration) was used to evaluate the quality of the included studies. A $P$-value of $<0.05$ was considered statistically significant.

\section{Results}

Literature search. The initial search of PubMed and Web of Science databases yielded 589 articles. Of these, 168 were excluded due to repetitive publications, and 350 articles were excluded based on the inclusion/ exclusion criteria after reading the titles and abstracts: 263 did not associate VOCs as tools for the diagnosis of neoplasm of the digestive system; 46 were review articles; 28 were conference abstracts; 2 were letters; 10 were not based on human studies; 1 was non-English literature. A total of 35 articles were excluded after reading the full text: 14 were not of diagnostic research; 5 were research of non-digestive tract neoplasm; 16 articles contained insufficient data to form $2 \times 2$ tables. Finally, a total of 36 studies were included in our meta-analysis (Fig. 1).

Study characteristics. The $36^{12,29-63}$ included studies comprised of a total of 39 datasets that investigated 5 cancer types: 3 on liver cancer, 16 on colorectal cancer, 10 on gastric cancer, 4 on esophageal cancer, and 6 on pancreatic cancer. Overall, our meta-analysis was performed based on 1712 cases and 3215 controls from 11 different countries. As for the origin of the VOCs measurements, 4 datasets measured VOCs patterns in feces, 
22 (from 21 studies) in exhaled breaths, 8 (from 7 studies) in urine, 1 in blood, 2 (from 1 study) in saliva, 1 in bowel gas, and 1 in bile.

There were 2 datasets that used the electronic nose as the analytical platform, 16 datasets (from 15 studies) used gas chromatography coupled with mass spectrometry (GC-MS), 5 datasets used field asymmetric ion mobility spectrometer (FAIMS), 8 datasets (from 7 studies) used selected ion flow tube mass spectrometer (SIFT-MS), and 8 studies used other analytical platforms: 2 datasets used silicon nanowire field-effect transistor (SINW-FET), 1 dataset used proton transfer reaction mass spectrometer (PTR-MS), 1 dataset used ion-molecule reaction mass spectrometry (IMR-MS), 1 dataset used single-photon ionization mass spectrometry (SPI-MS), 1 dataset used field asymmetric ion mobility spectrometer-mass spectrometry (FAIMS-MS) and 2 datasets used sensor (Table 1).

Risk of bias and quality assessment. There was no apparent publication bias between the included studies, given that the funnel chart was well-proportioned with a $P$-value of greater than 0.39 (see Supplemental Fig. S1). The analysis using the QUADAS-2 tool showed a low risk of bias and moderate to a high quality of the included studies (see Supplemental Fig. S2).

Diagnostic effect. Diagnostic accuracy was estimated using several indicators, including sensitivity, specificity, PLR, NLR, and DOR. The pooled sensitivity and specificity of VOCs for diagnosing neoplasm of the digestive system were 0.87 (95\% CI 0.83-0.90) and 0.86 (95\% CI 0.82-0.89), respectively (Fig. 2), while the pooled PLR and NLR were 6.18 (95\% CI 4.68-8.17) and 0.15 (95\% CI 0.12-0.20), respectively (Fig. 3). Furthermore, the pooled DOR (see Supplemental Fig. S3) and AUC (Fig. 4) were 40.61 (95\% CI 24.77-66.57) and 0.93 (95\% CI 0.90-0.95), respectively.

Heterogeneity. Heterogeneity existed in the pooled specificity $\left(\mathrm{I}^{2}=71.04 \%, P=0.00\right)$, as well as the pooled results of sensitivity $\left(\mathrm{I}^{2}=87.23 \%, P=0.00\right)$ (Fig. 2).

Meta-regression and subgroup analysis. Univariate meta-regression and subgroup analyses were performed to investigate potential sources of heterogeneity between studies. The forest plots (see Supplemental Fig. S4) of univariate meta-regression indicated that race, sample size, analytical platforms (MS, ISM, Sensor), VOCs source (exhaled breath, feces, urine, others), and the control groups (healthy individuals and non-cancer/ benign disease cohort) could be the sources of the heterogeneity. Factors including race, analytical platform, and VOCs source were included in the subgroup analysis (Table 2). Both the sensitivity and specificity in Asian (0.88, 95\% CI 0.82-0.92; and 0.91, 95\% CI 0.81-0.96, respectively) were higher than that in European and American (0.86, 95\% CI $0.82-0.90$; and $0.84,95 \%$ CI $0.80-0.88$, respectively). With regards to the source of VOCs, the sensitivity and specificity $(0.87,95 \%$ CI $0.82-0.91$; and $0.87,95 \%$ CI $0.83-0.91$, respectively) were the highest when VOCs were derived from exhaled breaths in the screening for tumors of the digestive system tumors. For the analytical platform, the sensitivity and specificity $(0.89,95 \%$ CI $0.85-0.92$; and $0.88,95 \%$ CI $0.84-0.91$, respectively) were the highest when VOCs were analyzed with MS.

\section{Discussion}

VOCs as biomarkers have been explored in recent years and are regarded as a new frontier in cancer diagnosis. It has great potentials in developing into a rapid, noninvasive, and inexpensive cancer diagnostic tool ${ }^{64,65}$. A recent meta-analysis has demonstrated a sensitivity of 0.79 and specificity of 0.89 in diagnosing cancer using VOCs analysis ${ }^{24}$. Also, in diagnosing colorectal cancer, another meta-analysis has revealed the sensitivity and specificity of VOCs being 0.82 and 0.79 , respectively ${ }^{26}$. Compared with the study by Zhou et al. ${ }^{26}$ that included studies of a single tumor, our meta-analysis included clinical studies of five different tumor types of the digestive system. Also, contrary to the study by Hanna et al. ${ }^{24}$, the sources of VOCs in our study were not limited to exhaled gases only but also included feces, blood, and urine. Furthermore, the number of studies included in our meta-analysis was also higher.

From the retrieved data of the included studies, we performed calculations on the sensitivity, specificity, PLR, NLR, and DOR to estimate the diagnostic accuracy of VOCs as a screening tool for tumors of the digestive system. From our analysis, the pooled sensitivity and specificity were 0.87 and 0.86 , respectively. Moreover, the overall diagnostic performance was assessed using the SROC curve, which revealed an AUC of 0.93, indicating excellent diagnostic performance. The DOR represented a single measure of test accuracy, which in our analysis, the DOR was 40.61 (DOR > 10), indicating great discriminatory test capability. Furthermore, the likelihood ratio and post-test probability indicated the risk of tumors of the digestive system when tested positive or negative. Our analysis revealed a PLR of 6, indicating that patients with digestive system tumors were six times more likely to test positive than healthy individuals. Coupled with the NLR of 0.15 , VOCs analysis represented a promising method to diagnose the neoplasm of the digestive system.

To identify potential sources of heterogeneity, univariate meta-regression and meta-analysis were performed, which revealed that factors including race, sample size, source of VOCs, analytical platforms, and types of the control group might be sources of heterogeneity in our meta-analysis. Further analysis demonstrated higher specificity for VOCs in the screening of tumors in the digestive system tumors of the Asians than the others (Europeans and Americans), suggesting that the performance of VOCs in cancer screening may vary according to race or ethnicity. Also, we found that analysis of VOCs from the exhaled breath performed better than other sources of VOCs. However, the sample size of studies investigating other sources of VOCs was smaller compared with those of VOCs from exhaled breath. For the analytical platform, the use of MS (mass spectrometry) to analyze VOCs had the highest sensitivity and specificity compared with other platforms. However, the sample size of 


\begin{tabular}{|c|c|c|c|c|c|c|c|c|c|c|c|c|c|}
\hline Author & Year & Country & $\begin{array}{l}\text { Gender } \\
\text { (\%male) }\end{array}$ & Mean age & $\mathrm{Tp}$ & Fp & Fn & Tn & Cancer type & VOC sources & $\begin{array}{l}\text { Analytical } \\
\text { platform }\end{array}$ & Control type & Sample size \\
\hline Xue et al. ${ }^{27}$ & 2008 & China & 100 & 50.5 & 18 & 0 & 1 & 18 & Liver cancer & Blood & GC-MS & Health & 37 \\
\hline Qin et al. ${ }^{28}$ & 2010 & China & 76 & 50.9 & 26 & 3 & 4 & 33 & Liver cancer & Exhaled breath & GC-MS & Health & 66 \\
\hline $\begin{array}{l}\text { Altomare } \\
\text { et al. }{ }^{29}\end{array}$ & 2013 & Italy & 42 & 55 & 32 & 7 & 5 & 34 & $\begin{array}{l}\text { Colorectal } \\
\text { cancer }\end{array}$ & Exhaled breath & GC-MS & Health & 78 \\
\hline Xu et al. ${ }^{30}$ & 2013 & China & 38 & 53.5 & 33 & 9 & 4 & 84 & Gastric cancer & Exhaled breath & GC-MS & Non-cancer & 130 \\
\hline $\begin{array}{l}\text { Arasaradnam } \\
\text { et al. } .^{31}\end{array}$ & 2014 & U.K & 56 & 53.5 & 73 & 20 & 10 & 30 & $\begin{array}{l}\text { Colorectal } \\
\text { Cancer }\end{array}$ & Urine & FAIMS & Health & 133 \\
\hline de Meij et al. ${ }^{32}$ & 2014 & Netherlands & 32 & 60 & 34 & 7 & 6 & 50 & $\begin{array}{l}\text { Colorectal } \\
\text { cancer }\end{array}$ & Feces & GC-MS & Health & 97 \\
\hline Batty et al. ${ }^{33}$ & 2015 & U.K & - & - & 24 & 9 & 7 & 22 & $\begin{array}{l}\text { Colorectal } \\
\text { cancer }\end{array}$ & Feces & SIFT-MS & Health & 62 \\
\hline Bhatt et al. ${ }^{34}$ & 2015 & America & 54 & 59.4 & 17 & 2 & 3 & 17 & $\begin{array}{l}\text { Esophageal } \\
\text { Adenocarci- } \\
\text { noma }\end{array}$ & Exhaled breath & SIFT-MS & Non-cancer & 39 \\
\hline Kumar et al. $\mathbf{I}^{12}$ & 2015 & U.K & 63 & 61.2 & 33 & 13 & 0 & 100 & Gastric cancer & Exhaled breath & SIFT-MS & Non-cancer & 146 \\
\hline Kumar et al.II $\mathbf{I}^{12}$ & 2015 & U.K & 67 & 64 & 47 & 22 & 1 & 107 & $\begin{array}{l}\text { Esophageal } \\
\text { Adenocarci- } \\
\text { noma }\end{array}$ & Exhaled breath & SIFT-MS & Non-cancer & 177 \\
\hline Shehada et al. ${ }^{35}$ & 2015 & Latvia & - & - & 5 & 2 & 2 & 17 & Gastric cancer & Exhaled breath & SINW-FET & Non-cancer & 26 \\
\hline Amal et al. ${ }^{36}$ & 2016 & Latvia & - & 63 & 17 & 2 & 3 & 34 & $\begin{array}{l}\text { Colorectal } \\
\text { cancer }\end{array}$ & Exhaled breath & GC-MS & Health & 56 \\
\hline Chen et al. ${ }^{37}$ & 2016 & China & 72 & 45 & 121 & 3 & 23 & 53 & Gastric cancer & Exhaled breath & GC-MS & Health & 200 \\
\hline Shehada et al. ${ }^{38}$ & 2016 & $\begin{array}{l}\text { Latvia; U.K; } \\
\text { Israel }\end{array}$ & 79 & 62.5 & 35 & 3 & 5 & 126 & Gastric cancer & Exhaled breath & SINW-FET & Health & 169 \\
\hline Zou et al. ${ }^{39}$ & 2016 & China & 47 & 58.4 & 25 & 6 & 4 & 51 & $\begin{array}{l}\text { Esophageal } \\
\text { cancer }\end{array}$ & Exhaled breath & PTR-MS & Health & 86 \\
\hline $\begin{array}{l}\text { Arasaradnam } \\
\text { et al. } .^{40}\end{array}$ & 2018 & UK & 42 & 57.9 & 74 & 14 & 7 & 67 & $\begin{array}{l}\text { Pancreatic } \\
\text { cancer }\end{array}$ & Urine & FAIMS & Health & 162 \\
\hline $\begin{array}{l}\text { Duran-Ace- } \\
\text { vedo et al. }{ }^{41}\end{array}$ & 2018 & Colombia & 59 & 69.8 & 14 & 1 & 0 & 14 & Gastric cancer & Exhaled breath & GC-MS & Non-cancer & 29 \\
\hline Ishibe et al. ${ }^{42}$ & 2018 & Japan & 70 & 50 & 27 & 11 & 3 & 15 & $\begin{array}{l}\text { Colorectal } \\
\text { cancer }\end{array}$ & Bowel gas & GC-MS & Health & 56 \\
\hline Markar et al..$^{43}$ & 2018 & U.K & 61 & 63 & 26 & 13 & 6 & 19 & $\begin{array}{l}\text { Pancreatic } \\
\text { cancer }\end{array}$ & Exhaled breath & GC-MS & Non-cancer & 64 \\
\hline Markar et al..$^{44}$ & 2018 & U.K & 64 & - & 130 & 33 & 33 & 139 & $\begin{array}{l}\text { Esophagogas- } \\
\text { tric cancer }\end{array}$ & Exhaled breath & SIFT-MS & Health & 335 \\
\hline $\begin{array}{l}\text { Princivalle } \\
\text { et al. }{ }^{45}\end{array}$ & 2018 & Italy & 52 & 57 & 65 & 16 & 0 & 86 & $\begin{array}{l}\text { pancreatic } \\
\text { cancer }\end{array}$ & Exhaled breath & IMR-MS & Health & 167 \\
\hline $\begin{array}{l}\text { Schuermans } \\
\text { et al. }{ }^{46}\end{array}$ & 2018 & China & 50 & 47 & 13 & 8 & 3 & 20 & Gastric cancer & Exhaled breath & E-nose & Health & 44 \\
\hline Widlak et al. ${ }^{47}$ & 2018 & U.K & - & - & 22 & 86 & 13 & 147 & $\begin{array}{l}\text { Colorectal } \\
\text { cancer }\end{array}$ & Urine & FAIMS & Health & 268 \\
\hline Bond et al. ${ }^{48}$ & 2019 & U.K & 40 & 67.3 & 18 & 9 & 3 & 51 & $\begin{array}{l}\text { Colorectal } \\
\text { cancer }\end{array}$ & Feces & GC-MS & Health & 81 \\
\hline Broza et al. ${ }^{49}$ & 2019 & Latvia & - & - & 3 & 153 & 0 & 570 & Gastric cancer & Exhaled breath & Sensor & Non-cancer & 726 \\
\hline Markar et al. ${ }^{50}$ & 2019 & U.K & - & - & 21 & 8 & 4 & 46 & $\begin{array}{l}\text { Colorectal } \\
\text { cancer }\end{array}$ & Exhaled breath & SIFT-MS & Non-cancer & 79 \\
\hline $\begin{array}{l}\text { McFarlane } \\
\text { et al. }\end{array}$ & 2019 & U.K & 47 & 58.7 & 39 & 25 & 17 & 57 & $\begin{array}{l}\text { Colorectal } \\
\text { cancer }\end{array}$ & Urine & FAIMS-MS & Health & 138 \\
\hline $\begin{array}{l}\text { Mozdiak et al. } \\
\text { I }^{52}\end{array}$ & 2019 & U.K & - & - & 8 & 4 & 2 & 20 & $\begin{array}{l}\text { Colorectal } \\
\text { cancer }\end{array}$ & Urine & GC-MS & Health & 34 \\
\hline $\begin{array}{l}\text { Mozdiak et al. } \\
\text { II }^{52}\end{array}$ & 2019 & U.K & - & - & 12 & 1 & 0 & 11 & $\begin{array}{l}\text { Colorectal } \\
\text { cancer }\end{array}$ & Urine & FAIMS & Health & 24 \\
\hline Nissinen et al..$^{53}$ & 2019 & Finland & 50 & 64.5 & 54 & 11 & 14 & 41 & $\begin{array}{l}\text { Pancreatic } \\
\text { Cancer }\end{array}$ & Urine & FAIMS & Health & 120 \\
\hline $\begin{array}{l}\text { Altomare } \\
\text { et al. }{ }^{54}\end{array}$ & 2020 & Italy & - & - & 74 & 6 & 8 & 81 & $\begin{array}{l}\text { Colorectal } \\
\text { cancer }\end{array}$ & Exhaled breath & GC-MS & Health & 169 \\
\hline $\begin{array}{l}\text { Bel'skaya et al. } \\
\text { I }^{55}\end{array}$ & 2020 & Russia & - & - & 9 & 0 & 2 & 16 & Gastric cancer & Saliva & GC-MS & Health & 27 \\
\hline $\begin{array}{l}\text { Bel'skaya et al. } \\
\text { II }^{55}\end{array}$ & 2020 & Russia & - & - & 17 & 0 & 1 & 16 & $\begin{array}{l}\text { Colorectal } \\
\text { cancer }\end{array}$ & Saliva & GC-MS & Health & 34 \\
\hline Hong et al. ${ }^{56}$ & 2020 & China & - & - & 28 & 1 & 1 & 23 & Gastric cancer & Exhaled breath & SPI-MS & Health & 53 \\
\hline $\begin{array}{l}\text { Miller-Atkins } \\
\text { et al. } .^{57}\end{array}$ & 2020 & America & - & - & 67 & 46 & 25 & 114 & Liver cancer & Exhaled breath & SIFT-MS & Non-cancer & 252 \\
\hline $\begin{array}{l}\text { Navaneethan } \\
\text { et al. }{ }^{58}\end{array}$ & 2020 & America & 58 & 62.9 & 19 & 0 & 0 & 12 & $\begin{array}{l}\text { Pancreatic } \\
\text { Cancer }\end{array}$ & Bile & SIFT-MS & Non-cancer & 31 \\
\hline \multicolumn{14}{|l|}{ Continued } \\
\hline
\end{tabular}




\begin{tabular}{|l|l|l|l|l|l|l|l|l|l|l|l|l|l|}
\hline Author & Year & Country & $\begin{array}{l}\text { Gender } \\
(\% \text { male })\end{array}$ & Mean age & Tp & Fp & Fn & Tn & Cancer type & VOC sources & $\begin{array}{l}\text { Analytical } \\
\text { platform }\end{array}$ & Control type & Sample size \\
\hline $\begin{array}{l}\text { van Keulen } \\
\text { et al. }{ }^{9}\end{array}$ & 2020 & Netherlands & 61 & - & 16 & 4 & 13 & 23 & $\begin{array}{l}\text { Colorectal } \\
\text { cancer }\end{array}$ & Exhaled breath & E-nose & Health & 56 \\
\hline Zonta et al. $^{60}$ & 2020 & Italy & - & - & 116 & 46 & 22 & 214 & $\begin{array}{l}\text { Colorectal } \\
\text { cancer }\end{array}$ & Feces & Sensor & Health & 398 \\
\hline Daulton et al..$^{61}$ & 2021 & U.K & 47 & 57 & 38 & 2 & 7 & 31 & $\begin{array}{l}\text { Pancreatic } \\
\text { cancer }\end{array}$ & Urine & GC-MS & Health & 78 \\
\hline
\end{tabular}

Table 1. Major characteristics of included studies. VOCs volatile organic compounds, GC-MS gas chromatography and mass spectrometry, FAIMS field asymmetric ion mobility spectrometer, SIFT-MS selected ion flow tube mass spectrometer, SINW-FET silicon nanowire field effect transistor, PTR-MS proton transfer reaction mass spectrometer, IMR-MS ion-molecule reaction mass spectrometry, SPI-MS single photon ionization mass spectrometry, $T n$ true negative, $T p$ true positive, $F p$ false positive, $F n$ false negative.

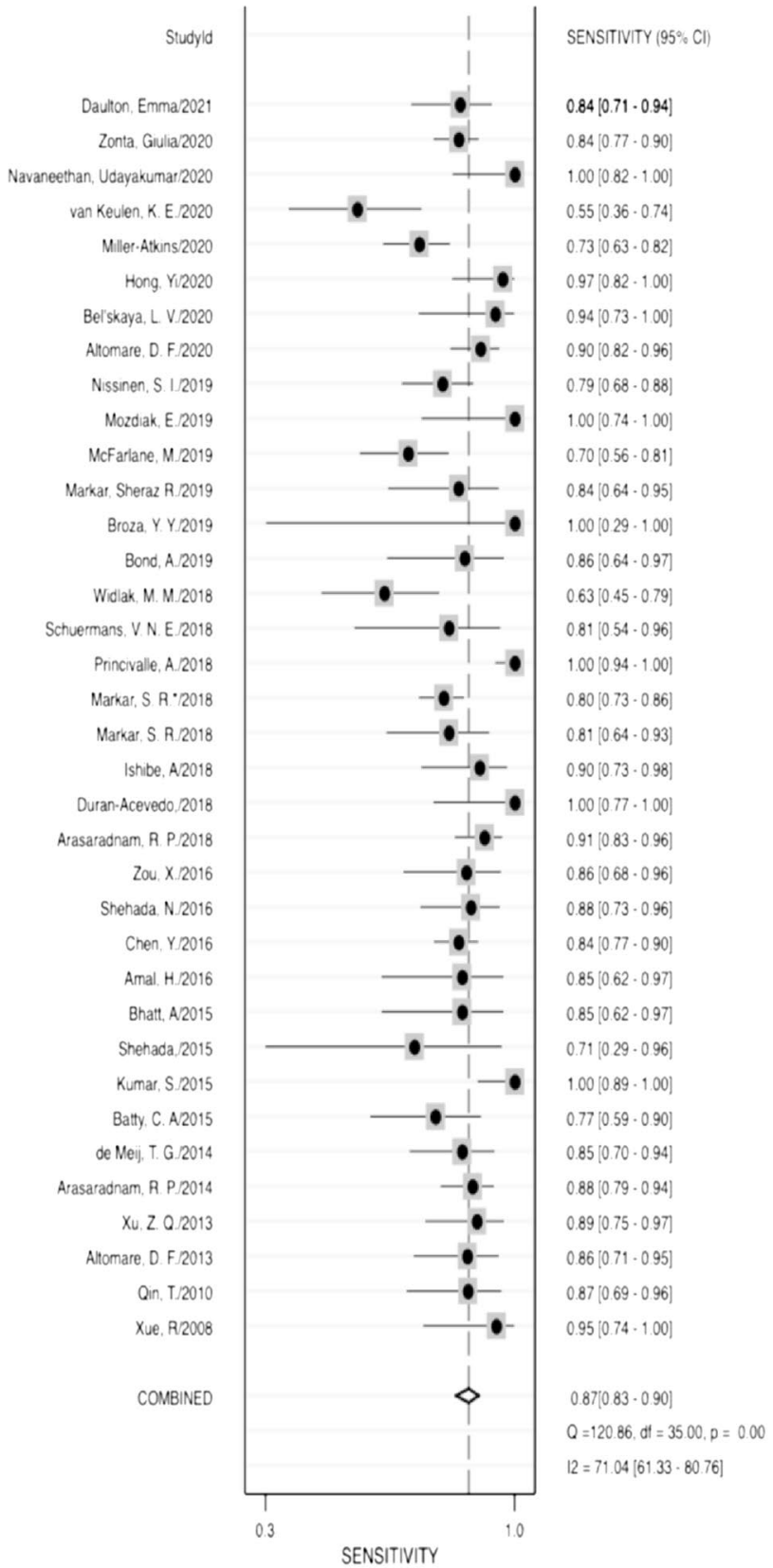

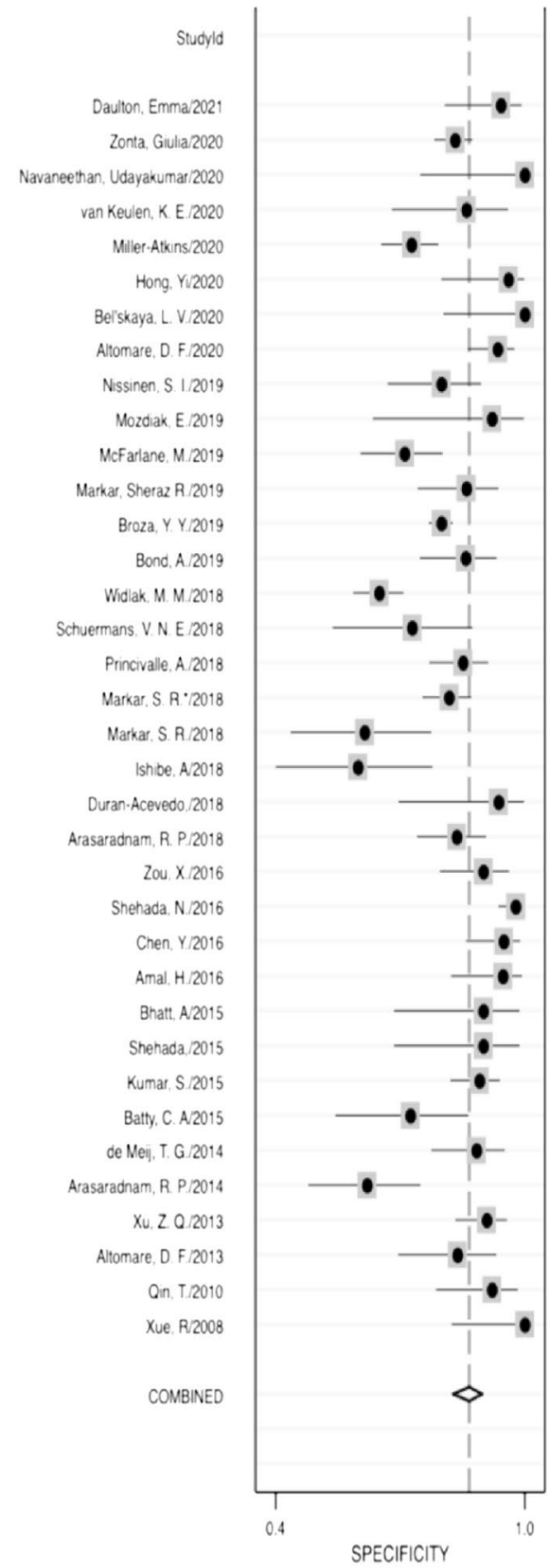

SPECIFICITY $(95 \% \mathrm{Cl})$

$0.94[0.80 \cdot 0.99]$

$0.82[0.77 \cdot 0.87]$

$1.00[0.74 \cdot 1.00]$

$0.85[0.66 \cdot 0.96]$

$0.71[0.64 \cdot 0.78]$

$0.96[0.79 \cdot 1.00]$

$1.00[0.79 \cdot 1.00]$

$0.93[0.86 \cdot 0.97]$

$0.79[0.65 \cdot 0.89]$

$0.92[0.62 \cdot 1.00]$

$0.70[0.58 \cdot 0.79]$

$0.85[0.73 \cdot 0.93]$

$0.79[0.76 \cdot 0.82]$

$0.85[0.73 \cdot 0.93]$

$0.63[0.57 \cdot 0.69]$

$0.71[0.51 \cdot 0.87]$

$0.84[0.76 \cdot 0.91]$

$0.81[0.74 \cdot 0.86]$

$0.59[0.41 \cdot 0.76$

$0.58[0.37 \cdot 0.77]$

$0.93[0.68 \cdot 1.00]$

$0.83[0.73 \cdot 0.90]$

$0.89[0.78 \cdot 0.96]$

$0.98[0.93 \cdot 1.00]$

$0.95[0.85 \cdot 0.99]$

$0.94[0.81 \cdot 0.99]$

$0.89[0.67 \cdot 0.99]$

$0.89[0.67 \cdot 0.99]$

$0.88[0.81 \cdot 0.94]$

$0.71[0.52 \cdot 0.86]$

$0.88[0.76 \cdot 0.95]$

$0.60[0.45 \cdot 0.74]$

$0.90[0.82 \cdot 0.95]$

$0.83[0.68 \cdot 0.93]$

$0.92[0.78 \cdot 0.98]$

$1.00[0.81 \cdot 1.00]$

$0.86|0.82 \cdot 0.89|$

$Q=274.03, d f=35.00, p=0.00$

$12=87.23[83.82 \cdot 90.64$

Figure 2. Forest plots of pooled sensitivity and specificity. 


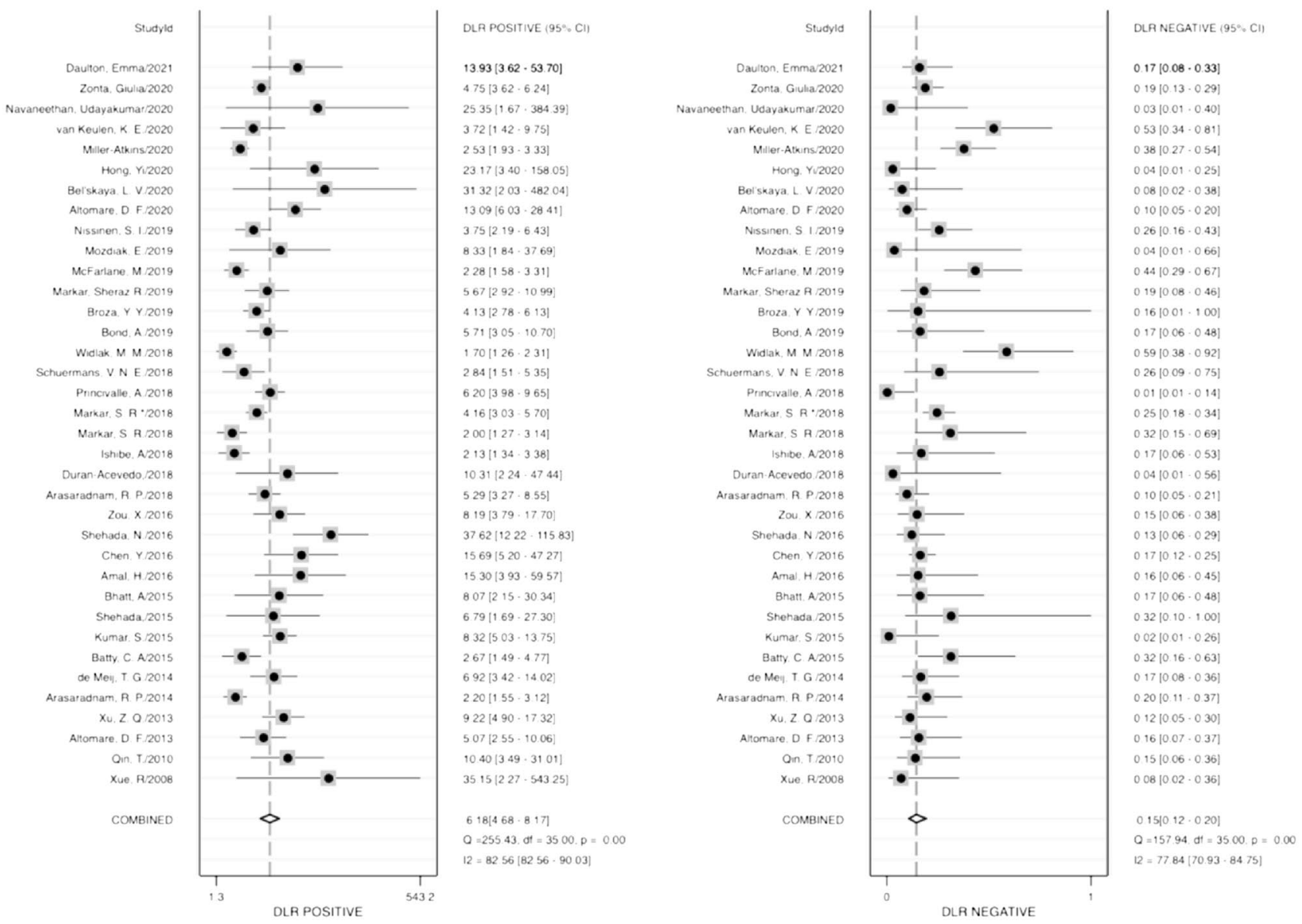

Figure 3. Forest plots of pooled positive likelihood radio and negative likelihood ratio.

studies utilizing MS was also much larger than that of other analytical platforms. In our study, the performance of VOCs as a screening tool for different tumors was not analyzed, given that our objective was to explore VOCs analysis as a rapid and non-invasive screening tool for tumors of the digestive system, with its applicability as a primary population screening rather than as a diagnostic tool for individual tumor types.

There were several reasons why this meta-analysis did not conduct threshold effect analysis: (1) different studies used different instruments for analyzing organic matter; (2) different instruments detected different types of organic matter; (3) different studies had different ways of setting the threshold value of organic compounds. Therefore, it was difficult to analyze the diagnostic ability of specific organic compounds for tumors. However, this did not affect the results that VOCs have good diagnostic ability in the digestive system.

Compared with other tumor markers currently applied in clinical practice, VOCs have demonstrated superior diagnostic ability in screening for gastric cancer and colorectal cancer. Serum pepsinogen is a widely used biomarker with good diagnostic efficacy for gastric cancer screening, with a meta-analysis demonstrating a sensitivity of 0.69 and a specificity of 0.73 , while the sensitivity and specificity could be improved further to 0.70 and 0.79 respectively when applying the ratio of PG I to PG II concentrations ${ }^{66}$. Besides, the combination of CA199 with CA242 has demonstrated a sensitivity of 0.90 and a specificity of $0.76^{67}$. From our analyses, the sensitivity (0.90) and specificity (0.91) of VOCs for gastric cancer, and the sensitivity (0.84) and specificity (0.82) of VOCs for colorectal cancer exhibited superior performance to conventional biomarkers in screening for neoplasm.

There were limitations to our study. The included studies were mostly of case-control and cross-sectional nature, with few prospective longitudinal studies to associate VOCs with disease severity. Second, only articles in the English language had been selected, which invariably resulted in selection bias. Third, the cancer types, and analytical platforms of tumor-associated VOCs also varied between the studies. Therefore, we did not analyze the performance of varying VOCs in screening for different tumors of the digestive system.

Therefore, further studies are warranted to not only innovate and combine advanced technologies in the sampling, detection, and analysis of VOCs but also to standardize these methods. Moreover, it is vital to explore the differences of VOCs between varying types and stages of tumors. Clinical trials would then be required for the validation of results before widespread clinical application.

\section{Conclusion}

The pooled results of our meta-analysis have confirmed the difference in the VOCs analysis between patients with tumors of the digestive system and healthy individuals, which sheds light on VOCs analysis as a promising novel screening tool for early detection of tumors. 


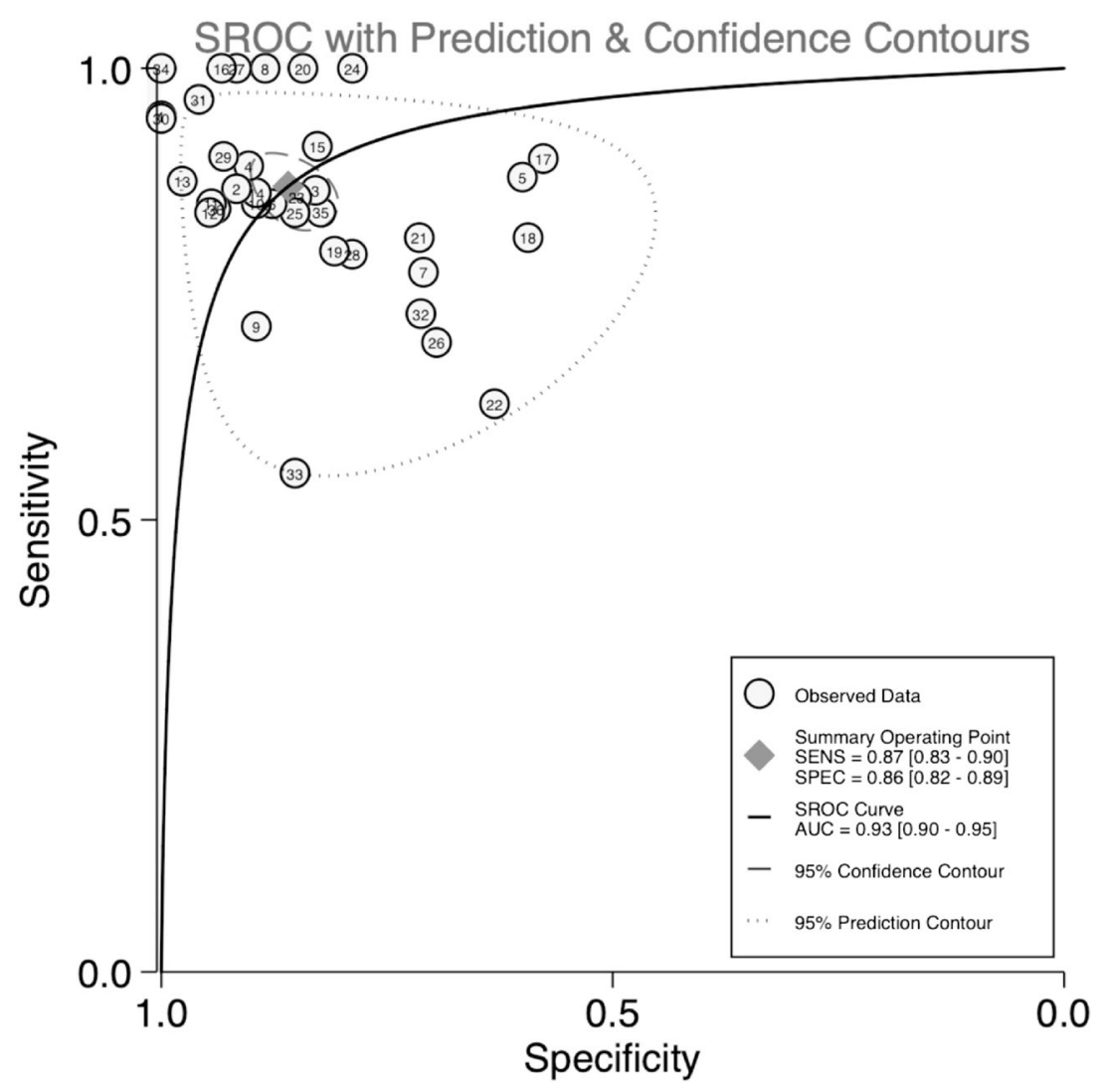

Figure 4. SROC curve of VOCs for the diagnosis of digestive system cancer. Abbreviations: The numbers in the circles represent the studies included in the paper. The eighth study corresponds to reference ${ }^{12}$, and the remaining studies ${ }^{1-11,13-36}$ correspond to reference ${ }^{27-61}$. VOCs: Volatile organic compounds.

\begin{tabular}{|l|l|l|l|l|}
\hline Subgroup & No. studies & No. sample sizes & Sensitivity value & Specificity value \\
\hline Race & \multicolumn{5}{|l|}{$\mid$} \\
\hline European and American & 27 & 3983 & $0.86(0.82-0.90)$ & $0.84(0.80-0.88)$ \\
\hline Asian & 9 & 706 & $0.88(0.82-0.92)$ & $0.91(0.81-0.96)$ \\
\hline VOCs source & 21 & 3001 & $0.87(0.82-0.91)$ & $0.87(0.83-0.91)$ \\
\hline Exhaled breath & 4 & 638 & $0.83(0.78-0.88)$ & $0.83(0.79-0.86)$ \\
\hline Faeces & 7 & 933 & $0.82(0.73-0.88)$ & $0.76(0.67-0.83)$ \\
\hline Urine & 4 & 158 & - & - \\
\hline Other source & \multicolumn{5}{|l|}{} & \\
\hline Analysis platform & 25 & 2459 & $0.89(0.85-0.91)$ & $0.88(0.84-0.91)$ \\
\hline MS & 5 & 707 & $0.86(0.73-0.93)$ & $0.75(0.64-0.84)$ \\
\hline IMS & 6 & 1419 & $0.79(0.67-0.88)$ & $0.86(0.75-0.93)$ \\
\hline Sonsers & \multicolumn{5}{|l|}{} \\
\hline
\end{tabular}

Table 2. Subgroup analysis of diagnostic effect. Data selection in subgroup analysis of race group: Samples in three studies were from the same race group. My data extraction: Kumar S 2015 selected gastric cancer samples; Mozdiak E 2019 selects FAIMS samples; Bel'skaya LV 2020 selected colorectal cancer sample. Data selection in subgroup analysis of VOCS source: Samples in three studies were from the same VOCs source group. My data extraction: Kumar S 2015 selected esophageal Adenocarcinoma samples; Mozdiak E 2019 selected GC-MS samples; Bel'skaya LV 2020 selected colorectal cancer sample. Data selection in subgroup analysis of analysis platform: My data extraction: Data from two different analysis platforms in Kumar S 2015 and Mozdiak E 2019 were extracted; The platform of McFarlane M 2019 was combined with FAIMS and MS, so it was not included in any group of the analysis platform subgroup; Because two sets of data in the study of Bel'skaya LV were based on GC-MS platform, we selected colorectal cancer samples. MS mass spectrometry, IMS ion mobility spectrometer, VOCs volatile organic compounds. 


\section{Data availability}

All data generated or analyzed during this study are included in this published article and its supplementary information.

Received: 9 March 2021; Accepted: 24 November 2021

Published online: 09 December 2021

\section{References}

1. Bray, F. et al. Global cancer statistics 2018: GLOBOCAN estimates of incidence and mortality worldwide for 36 cancers in 185 countries. CA Cancer J. Clin. 68, 394-424. https://doi.org/10.3322/caac.21492 (2018).

2. Jing, J. X. et al. Tumor markers for diagnosis, monitoring of recurrence and prognosis in patients with upper gastrointestinal tract cancer. Asian Pac. J. Cancer Prev. 15, 10267-10272. https://doi.org/10.7314/apjcp.2014.15.23.10267 (2014).

3. Yin, L. K., Sun, X. Q. \& Mou, D. Z. Value of combined detection of serum CEA, CA72-4, CA19-9 and TSGF in the diagnosis of gastric cancer. Asian Pac. J. Cancer Prev. 16, 3867-3870. https://doi.org/10.7314/apjcp.2015.16.9.3867 (2015).

4. Łukaszewicz-Zając, M., Mroczko, B., Kozłowski, M. \& Szmitkowski, M. The serum concentrations of chemokine CXCL12 and its specific receptor CXCR4 in patients with esophageal cancer. Dis. Mark. 2016, 7963895. https://doi.org/10.1155/2016/7963895 (2016).

5. Mohammadi, P. et al. A pilot study of CK19, CK20 and GCC mRNA in the peripheral blood as a colorectal cancer biomarker panel. Int. J. Mol. Cell Med. 5, 30-36 (2016).

6. Wen, Q., Boshier, P., Myridakis, A., Belluomo, I. \& Hanna, G. B. Urinary volatile organic compound analysis for the diagnosis of cancer: A systematic literature review and quality assessment. Metabolites https://doi.org/10.3390/metabo11010017 (2020).

7. Rondanelli, M. et al. Volatile organic compounds as biomarkers of gastrointestinal diseases and nutritional status. J. Anal. Methods Chem. 2019, 7247802. https://doi.org/10.1155/2019/7247802 (2019).

8. Oakley-Girvan, I. \& Davis, S. W. Breath based volatile organic compounds in the detection of breast, lung, and colorectal cancers: A systematic review. Cancer Biomark. 21, 29-39. https://doi.org/10.3233/cbm-170177 (2017).

9. Cicolella, A. Volatile organic compounds (VOC): Definition, classification and properties. Rev. Mal. Respir. 25, 155-163. https:// doi.org/10.1016/s0761-8425(08)71513-4 (2008).

10. Dummer, J. et al. Analysis of biogenic volatile organic compounds in human health and disease. Trac-Trends Anal. Chem. 30, 960-967. https://doi.org/10.1016/j.trac.2011.03.011 (2011).

11. Schantz, M. M. et al. Development of urine standard reference materials for metabolites of organic chemicals including polycyclic aromatic hydrocarbons, phthalates, phenols, parabens, and volatile organic compounds. Anal. Bioanal. Chem. 407, 2945-2954. https://doi.org/10.1007/s00216-014-8441-0 (2015).

12. Kumar, S. et al. Mass spectrometric analysis of exhaled breath for the identification of volatile organic compound biomarkers in esophageal and gastric adenocarcinoma. Ann. Surg. 262, 981-990. https://doi.org/10.1097/sla.0000000000001101 (2015).

13. Haick, H., Broza, Y. Y., Mochalski, P., Ruzsanyi, V. \& Amann, A. Assessment, origin, and implementation of breath volatile cancer markers. Chem. Soc. Rev. 43, 1423-1449. https://doi.org/10.1039/c3cs60329f (2014).

14. Nakhleh, M. K. et al. Diagnosis and classification of 17 diseases from 1404 subjects via pattern analysis of exhaled molecules. ACS Nano 11, 112-125. https://doi.org/10.1021/acsnano.6b04930 (2017).

15. Boots, A. W., Bos, L. D., van der Schee, M. P., van Schooten, F. J. \& Sterk, P. J. Exhaled molecular fingerprinting in diagnosis and monitoring: Validating volatile promises. Trends Mol. Med. 21, 633-644. https://doi.org/10.1016/j.molmed.2015.08.001 (2015).

16. Buljubasic, F. \& Buchbauer, G. The scent of human diseases: A review on specific volatile organic compounds as diagnostic biomarkers. Flavour Fragr. J. 30, 5-25. https://doi.org/10.1002/ff.3219 (2015).

17. Turner, C. Techniques and issues in breath and clinical sample headspace analysis for disease diagnosis. Bioanalysis 8, 677-690. https://doi.org/10.4155/bio.16.22 (2016).

18. Louis, P., Young, P., Holtrop, G. \& Flint, H. J. Diversity of human colonic butyrate-producing bacteria revealed by analysis of the butyryl-CoA:acetate CoA-transferase gene. Environ. Microbiol. 12, 304-314. https://doi.org/10.1111/j.1462-2920.2009.02066.x (2010).

19. Gagnière, J. et al. Gut microbiota imbalance and colorectal cancer. World J. Gastroenterol. 22, 501-518. https://doi.org/10.3748/ wjg.v22.i2.501 (2016).

20. Ríos-Covián, D. et al. Intestinal short chain fatty acids and their link with diet and human health. Front. Microbiol. 7, 185. https:// doi.org/10.3389/fmicb.2016.00185 (2016).

21. Smolinska, A. et al. Volatile metabolites in breath strongly correlate with gut microbiome in CD patients. Anal. Chim. Acta 1025, 1-11. https://doi.org/10.1016/j.aca.2018.03.046 (2018).

22. Kneepkens, C. M., Lepage, G. \& Roy, C. C. The potential of the hydrocarbon breath test as a measure of lipid peroxidation. Free Radic. Biol. Med. 17, 127-160. https://doi.org/10.1016/0891-5849(94)90110-4 (1994).

23. Toyokuni, S. Molecular mechanisms of oxidative stress-induced carcinogenesis: From epidemiology to oxygenomics. IUBMB Life 60, 441-447. https://doi.org/10.1002/iub.61 (2008).

24. Hanna, G. B., Boshier, P. R., Markar, S. R. \& Romano, A. Accuracy and methodologic challenges of volatile organic compoundbased exhaled breath tests for cancer diagnosis: A systematic review and meta-analysis. JAMA Oncol. 5, e182815. https://doi.org/ 10.1001/jamaoncol.2018.2815 (2019).

25. Haddad, G., Schouwenburg, S., Altesha, A., Xu, W. \& Liu, G. Using breath analysis as a screening tool to detect gastric cancer: A systematic review. J. Breath Res. https://doi.org/10.1088/1752-7163/abc4d5 (2020).

26. Zhou, W., Tao, J., Li, J. \& Tao, S. Volatile organic compounds analysis as a potential novel screening tool for colorectal cancer: A systematic review and meta-analysis. Med. (Baltim.) 99, e20937. https://doi.org/10.1097/md.0000000000020937 (2020).

27. Whiting, P. F. et al. QUADAS-2: A revised tool for the quality assessment of diagnostic accuracy studies. Ann. Intern. Med. 155, 529-536. https://doi.org/10.7326/0003-4819-155-8-201110180-00009 (2011).

28. Higgins, J. P. T., Thompson, S. G., Deeks, J. J. \& Altman, D. G. Measuring inconsistency in meta-analyses. Br. Med. J. 327, 557-560. https://doi.org/10.1136/bmj.327.7414.557 (2003).

29. Xue, R. et al. Investigation of volatile biomarkers in liver cancer blood using solid-phase microextraction and gas chromatography/ mass spectrometry. Rapid Commun. Mass Spectrom. 22, 1181-1186. https://doi.org/10.1002/rcm.3466 (2008).

30. Qin, T. et al. The screening of volatile markers for hepatocellular carcinoma. Cancer Epidemiol. Biomark. Prev. 19, $2247-2253$. https://doi.org/10.1158/1055-9965.Epi-10-0302 (2010).

31. Altomare, D. F. et al. Exhaled volatile organic compounds identify patients with colorectal cancer. Br. J. Surg. 100, 144-151. https:// doi.org/10.1002/bjs.8942 (2013).

32. Xu, Z. Q. et al. A nanomaterial-based breath test for distinguishing gastric cancer from benign gastric conditions. Br. J. Cancer 108, 941-950. https://doi.org/10.1038/bjc.2013.44 (2013).

33. Arasaradnam, R. P. et al. Detection of colorectal cancer (CRC) by urinary volatile organic compound analysis. PLoS ONE 9 , e108750. https://doi.org/10.1371/journal.pone.0108750 (2014). 
34. de Meij, T. G. et al. Electronic nose can discriminate colorectal carcinoma and advanced adenomas by fecal volatile biomarker analysis: Proof of principle study. Int. J. Cancer 134, 1132-1138. https://doi.org/10.1002/ijc.28446 (2014).

35. Batty, C. A., Cauchi, M., Lourenço, C., Hunter, J. O. \& Turner, C. Use of the analysis of the volatile faecal metabolome in screening for colorectal cancer. PLoS ONE 10, e0130301. https://doi.org/10.1371/journal.pone.0130301 (2015).

36. Bhatt, A. et al. Volatile organic compounds (VOCs) in plasma for diagnosis of esophageal adenocarcinoma (EAC) - A pilot study. Gastroenterology 148, S361-S361 (2015).

37. Shehada, N. et al. Ultrasensitive silicon nanowire for real-world gas sensing: Noninvasive diagnosis of cancer from breath volatolome. Nano Lett. 15, 1288-1295. https://doi.org/10.1021/nl504482t (2015).

38. Amal, H. et al. Breath testing as potential colorectal cancer screening tool. Int. J. Cancer 138, 229-236. https://doi.org/10.1002/ijc. 29701 (2016).

39. Chen, Y. et al. Breath analysis based on surface-enhanced Raman scattering sensors distinguishes early and advanced gastric cancer patients from healthy persons. ACS Nano 10, 8169-8179. https://doi.org/10.1021/acsnano.6b01441 (2016).

40. Shehada, N. et al. Silicon nanowire sensors enable diagnosis of patients via exhaled breath. ACS Nano 10, 7047-7057. https://doi. org/10.1021/acsnano.6b03127 (2016).

41. Zou, X. et al. Exhaled gases online measurements for esophageal cancer patients and healthy people by proton transfer reaction mass spectrometry. J. Gastroenterol. Hepatol. 31, 1837-1843. https://doi.org/10.1111/jgh.13380 (2016).

42. Arasaradnam, R. P. et al. Noninvasive diagnosis of pancreatic cancer through detection of volatile organic compounds in urine. Gastroenterology 154, 485-487.e481. https://doi.org/10.1053/j.gastro.2017.09.054 (2018).

43. Duran-Acevedo, C. M. et al. Exhaled breath analysis for gastric cancer diagnosis in Colombian patients. Oncotarget 9, 28805-28817. https://doi.org/10.18632/oncotarget.25331 (2018).

44. Ishibe, A. et al. Detection of gas components as a novel diagnostic method for colorectal cancer. Ann. Gastroenterol. Surg. 2, 147-153. https://doi.org/10.1002/ags3.12056 (2018).

45. Markar, S. R. et al. Profile of exhaled-breath volatile organic compounds to diagnose pancreatic cancer. Br. J. Surg. 105, 1493-1500. https://doi.org/10.1002/bjs.10909 (2018).

46. Markar, S. R. et al. Assessment of a noninvasive exhaled breath test for the diagnosis of oesophagogastric cancer. JAMA Oncol. 4, 970-976. https://doi.org/10.1001/jamaoncol.2018.0991 (2018).

47. Princivalle, A., Monasta, L., Butturini, G., Bassi, C. \& Perbellini, L. Pancreatic ductal adenocarcinoma can be detected by analysis of volatile organic compounds (VOCs) in alveolar air. BMC Cancer 18, 529. https://doi.org/10.1186/s12885-018-4452-0 (2018).

48. Schuermans, V. N. E. et al. Pilot study: Detection of gastric cancer from exhaled air analyzed with an electronic nose in chinese patients. Surg. Innov. 25, 429-434. https://doi.org/10.1177/1553350618781267 (2018).

49. Widlak, M. M. et al. Risk stratification of symptomatic patients suspected of colorectal cancer using faecal and urinary markers. Colorectal Dis. 20, O335-o342. https://doi.org/10.1111/codi.14431 (2018).

50. Bond, A. et al. Volatile organic compounds emitted from faeces as a biomarker for colorectal cancer. Aliment. Pharmacol. Ther. 49, 1005-1012. https://doi.org/10.1111/apt.15140 (2019).

51. Broza, Y. Y. et al. Screening for gastric cancer using exhaled breath samples. Br. J. Surg. 106, 1122-1125. https://doi.org/10.1002/ bjs.11294 (2019).

52. Markar, S. R. et al. Breath volatile organic compound profiling of colorectal cancer using selected ion flow-tube mass spectrometry. Ann. Surg. 269, 903-910. https://doi.org/10.1097/sla.0000000000002539 (2019).

53. McFarlane, M. et al. Urinary volatile organic compounds and faecal microbiome profiles in colorectal cancer. Colorectal Dis. 21, 1259-1269. https://doi.org/10.1111/codi.14739 (2019).

54. Mozdiak, E., Wicaksono, A. N., Covington, J. A. \& Arasaradnam, R. P. Colorectal cancer and adenoma screening using urinary volatile organic compound (VOC) detection: Early results from a single-centre bowel screening population (UK BCSP). Tech. Coloproctol. 23, 343-351. https://doi.org/10.1007/s10151-019-01963-6 (2019).

55. Nissinen, S. I. et al. Detection of pancreatic cancer by urine volatile organic compound analysis. Anticancer Res. 39, 73-79. https:// doi.org/10.21873/anticanres.13081 (2019).

56. Altomare, D. F. et al. Chemical signature of colorectal cancer: Case-control study for profiling the breath print. BJS Open https:// doi.org/10.1002/bjs5.50354 (2020).

57. Bel'skaya, L. V., Sarf, E. A., Shalygin, S. P., Postnova, T. V. \& Kosenok, V. K. Identification of salivary volatile organic compounds as potential markers of stomach and colorectal cancer: A pilot study. J. Oral Biosci. 62, 212-221. https://doi.org/10.1016/j.job.2020. $05.002(2020)$.

58. Hong, Y. et al. Exhaled breath analysis using on-line preconcentration mass spectrometry for gastric cancer diagnosis. J. Mass Spectrom. https://doi.org/10.1002/jms.4588 (2020).

59. Miller-Atkins, G. et al. Breath metabolomics provides an accurate and noninvasive approach for screening cirrhosis, primary, and secondary liver tumors. Hepatol. Commun. 4, 1041-1055. https://doi.org/10.1002/hep4.1499 (2020).

60. Navaneethan, U. et al. Volatile organic compounds in bile can distinguish pancreatic cancer from chronic pancreatitis: A prospective observational study. Eur. J. Phys. https://doi.org/10.1055/a-1255-9169 (2020).

61. van Keulen, K. E., Jansen, M. E., Schrauwen, R. W. M., Kolkman, J. J. \& Siersema, P. D. Volatile organic compounds in breath can serve as a non-invasive diagnostic biomarker for the detection of advanced adenomas and colorectal cancer. Aliment. Pharmacol. Ther. 51, 334-346. https://doi.org/10.1111/apt.15622 (2020).

62. Zonta, G. et al. Clinical validation results of an innovative non-invasive device for colorectal cancer preventive screening through fecal exhalation analysis. Cancers https://doi.org/10.3390/cancers12061471 (2020).

63. Daulton, E. et al. Volatile organic compounds (VOCs) for the non-invasive detection of pancreatic cancer from urine. Talanta https://doi.org/10.1016/j.talanta.2020.121604 (2021).

64. Turner, A. P. \& Magan, N. Electronic noses and disease diagnostics. Nat. Rev. Microbiol. 2, 161-166. https://doi.org/10.1038/nrmic ro823 (2004).

65. Amal, H. et al. Geographical variation in the exhaled volatile organic compounds. J. Breath Res. 7, 047102. https://doi.org/10.1088/ 1752-7155/7/4/047102 (2013).

66. Huang, Y. K. et al. Significance of serum pepsinogens as a biomarker for gastric cancer and atrophic gastritis screening: A systematic review and meta-analysis. PLoS ONE 10, e0142080. https://doi.org/10.1371/journal.pone.0142080 (2015).

67. Zhang, Y. et al. Tumor markers CA19-9, CA242 and CEA in the diagnosis of pancreatic cancer: A meta-analysis. Int. J. Clin. Exp. Med. 8, 11683-11691 (2015).

\section{Author contributions}

L.X.W. and Y.L.Z. conceived the study, participated in the design, collected and interpreted the data, and wrote the manuscript. J.A.L., X.L.X. and T.T.H. performed statistical analyses, interpretation of data, and helped to draft the manuscript. Z.G., C.Z. and L.L.Z. contributed to the development of the review concept and revised the manuscript critically for important intellectual content. All authors read and approved the final manuscript. 


\section{Funding}

This study was supported by the Natural Science Foundation of Jilin Province (No. 20180101101JC); Special Health Project of Jilin Provincial Finance Department (3D518V613429); Special Project of Medical and Health Personnel in Jilin Province (No. 2019SCZT026); Bethune Project (No. 419161900018) and Special Health Project of Jilin Province (No. 2020SCZT061).

\section{Competing interests}

The authors declare no competing interests.

\section{Additional information}

Supplementary Information The online version contains supplementary material available at https://doi.org/ 10.1038/s41598-021-02906-8.

Correspondence and requests for materials should be addressed to L.Z. or Y.Z.

Reprints and permissions information is available at www.nature.com/reprints.

Publisher's note Springer Nature remains neutral with regard to jurisdictional claims in published maps and institutional affiliations.

(c) (1) Open Access This article is licensed under a Creative Commons Attribution 4.0 International License, which permits use, sharing, adaptation, distribution and reproduction in any medium or format, as long as you give appropriate credit to the original author(s) and the source, provide a link to the Creative Commons licence, and indicate if changes were made. The images or other third party material in this article are included in the article's Creative Commons licence, unless indicated otherwise in a credit line to the material. If material is not included in the article's Creative Commons licence and your intended use is not permitted by statutory regulation or exceeds the permitted use, you will need to obtain permission directly from the copyright holder. To view a copy of this licence, visit http://creativecommons.org/licenses/by/4.0/.

(C) The Author(s) 2021 